s'interroger sur la valeur de cette bibliographie. Nous avons également du mal à dissiper un doute concernant l'exactitude des autres données qui n'ont pu être contrôlées faute de temps.

JACQUES MICHON

(Jacques Michon est professeur au Département d'études françaises de l'Université de Sherbrooke.)

Heather Boylan, comp. Checklist and Historical Directory of Prince Edward Island Newspapers, 1787-1986. Charlottetown: Public Archives of Prince Edward Island, I978. 2 I I pp.; price not listed (paper).

Checklist and Historical Directory of Prince Edward Island Newspapers, 1787-1986 is another in a series of inventories undertaken through the National Library of Canada's decentralized programme for Canadian newspapers. Others which have appeared are those of British Columbia, Newfoundland and Labrador, Manitoba and Ontario. The inventories from the remaining provinces and territories are at various states of progress.

Entries in this checklist, in contrast to other published inventories in this programme, are 'usually' by the most recent title of the paper. (The term 'usually' is not defined.) These current titles are cross-referenced to preceding titles or to what the compiler terms 'variant titles.' The introduction states that the checklist 'attempts to provide' dates of publication, location, frequency of publication, and the names of proprietors, editors, and publishers. Actually Boylan also provides, in some instances, the names of 'managers' and 'presidents.' This information is followed by a prospectus, often a brief paragraph, although infrequently this prospectus will run from two to three pages in length. Here Boylan outlines the 'subject matter and editorial biases' of a newspaper. Boylan concedes that a problem arose here when different sources offered contradictory opinions on some aspect of a newspaper. In these cases, the compiler states that 'the source which seemed most reliable was followed.' So much for empirical evidence. There are three Charlottetown locations cited in this volume: namely, the Confederation Centre Public Library, the Public Archives of Prince Edward Island and the University of Prince Edward Island. It is unfortunate that the Library codes adopted by the Library community have not been used here; rather the compiler's own acronyms have been established. The holdings section of each entry only cites microfilm copies where microfilm exists, and microfilm copy holdings are either 'copy positives' (for public use) or 'masters' (not available). It is unfortunate that originals are only noted where no microfilm exists. In several instances, the 'masters' are shorter in the time frame than are the 'copy positives.' For example, the 'masters' for the Prince Edward Island Register (p. I I 4) are for only one day; this newspaper was published for seven years and 'copy positives' are for those seven years. If applicable, the entry will include a note on missing issues, but only if those missing issues cumulate to a month or more. This is a separate entry; there is no such innovation as square brackets within the holdings entry. 
By all indications, the checklist follows the National Library of Canada's limited definition of 'newspaper,' although no such indication is given in the introduction. The volume is supplemented by two indexes. The first cites newspapers published outside Charlottetown. It would have been preferable to have compiled a complete geographical index. If a user wishes to know which newspaper or how many were published in Charlottetown, then that user will have to go through the volume page by page. Also, some newspapers have only Prince Edward Island cited as 'location.' Where do they fit? The other index is chronological and indicates which titles were published each year.

In addition to the above, it would have been useful to learn whether any indexes (complete or partial) have been compiled for any of these newspapers. There is a line in the introduction which mentions a 'newspaper card index,' but this may be a holdings list; no clarification is given. Some re-writing and better proof-reading would have clarified a number of ambiguous points. There are a number of spelling mistakes - Meighan (p. 17) for Meighen, Mechanics Institute (p. I39) for Mechanics' Institute, among others. The notation section devoted to 'missing' issues should have been much more specific. A line such as 'many issues [missing] between I 890 and $1892^{\prime}$ creates greater consternation than assistance. It would have been preferable to have spent more time on the bibliographical aspect of this checklist rather than on the 'biographical' or prospectus notation. And finally, the concept of typography is totally missing from this publication. There is no use of bold face or different type sizes. The most glaring eyesore is the use of 'see' references. For these pages the 'see' references sit in an upper corner of a blank page; at one point there are six consecutive pages of these.

Most of the basic information on Prince Edward Island newspapers is available in this checklist. With more rigorous scholarship, this could have been an excellent publication.

ERIC L. SWANICK

(Eric L. Swanick is the New Brunswick Legislative Librarian and Chair of the Marie Tremaine Medal Committee of the Bibliographical Society of Canada.)

\section{G. Blaine Baker, Kathleen E. Fisher, Vince Masciotra and Brian Young. Sources in the Law Library of McGill University for a Reconstruction of the Legal Culture of Quebec, 1760-1890. Montreal: Faculty of Law and Montreal Business History Project, McGill University, I987. ix, 276 pp.; gratis.}

This bibliography, the result of three years of shelf-searching, is an essential reference work for the historian of Quebec law and society. It is inspired by the notion that 'Lower Canadian law reposed in some measure in that society's literature of the law, and in the minds of provincial lawyers, judges and bureaucrats whose dialectic with that literature is displayed in their use and annotation of legal literature' (p. 2). Sources lists some 7,000 volumes, all of which were in circulation in Quebec between approximately 1760 and 1890 , and somehow found their way into the 